\title{
Clinical Laboratory Evaluation Program
}

National Cancer Institute

\section{Source}

National Cancer Institute. Clinical Laboratory Evaluation Program. NCI Thesaurus. Code C160785.

A program of the New York State Department of Health that administers the activities of the Clinical Laboratory Reference System and provides the oversight of over 1,000 clinical laboratories and blood banks, including out-of-state facilities that accept clinical specimens collected in New York State. CLEP seeks to ensure the accuracy and reliability of results of laboratory tests on specimens obtained within the state through on-site inspections, review of proficiency testing performance, and evaluation of the qualifications of personnel of state permit-holding clinical laboratories and blood banks. 